\title{
The Route Optimization of Multi-temperature Joint Distribution for Cold-Chain Products under the Condition of Random Driving Time
}

\author{
Guiwu Huang \\ College of Management \\ Wuhan University of Science and Technology \\ Hubei, China \\ 906924184@qq.com
}

\author{
Renshan Lu \\ College of Management \\ Wuhan University of Science and Technology \\ Hubei, China \\ lrsfrank@163.com
}

\begin{abstract}
In this paper, the problems of random travel time and cold-chain varieties and temperature difference in urban cold chain logistics distribution system are studied. First, we use the cold-accumulating multi-temperature co-distribution to distribute cold chain products with different temperature layers. Then, the vehicle travel time period under different road conditions is treated as a random variable subject to the known distribution, and the random path optimization of the multitemperature cold chain product based on the minimum distribution cost is constructed. In this paper, in addition to the study of time window constraints, the study of the rejection of goods because of cargo damage rate is also studied, so that delivery costs are better and more practical; finally, an example is used to verify the effectiveness of the model. Our results show that the model can be a good application in the dynamic environment of multi-temperature cold chain product optimization, with a certain degree of flexibility.
\end{abstract}

Keywords-Random travel time; multi-temperature codistribution; path optimization

\section{INTRODUCTION}

With the improvement of the rapid development of market economy and people's living standards, cold chain and types of product demand is growing. City cold chain distribution as a bridge between enterprises and customers, its operational efficiency and service level is essential. According to relevant researches [1-9], the emerging mode of cooling-storage multitemperature joint distribution has replaced the traditional mode of mechanical multi-temperature joint distribution. Besides saving the energy, reducing the emission and decreasing the cost of vehicle purchase, it also has the advantages of keeping the high quality and freshness as well as enlarging the distribution area. Hence, it has represented the new development direction of cold-chain logistics. Moreover, when moving in the city, the vehicle is often subject to the factors such as climate, geography, road condition and driver's ability. As a result, the driving time will vary greatly. By choosing the multi-temperature cold-chain products under the condition of random driving time as a research object, this paper has analyzed and solved the problem of route planning under the dynamic environment. It hopes to provide the theoretical basis and method guidance for the cold-chain distribution in Chinese cities.
For the cold chain distribution research, domestic and foreign scholars on the single product temperature cold chain products were fully studied, mainly from the cost structure, random environment, two-way distribution and model solving research breakthrough. With the development of urban cold chain and the rise of third-party logistics, multi-species, small quantities and multi-network multi-temperature co-operation came into being. In the cold storage of multi-temperature codistribution research, $\mathrm{CHO}$ draws on Taiwan's experience, put forward the feasibility of the storage of multi-temperature codistribution in operation; Kuo proposed cold storage multitemperature co-distribution is widely applicable to a variety of logistics services model; Hsu through an example to verify the storage of multi-temperature co-distribution for multi-species, small quantities of cold chain products distribution; Wang Shuyun and Zhao Min consider the dynamic mechanism of cold-accumulating multi-temperature co-distribution, which proves that the cold-accumulating multi-temperature codistribution can not only guarantee the product quality and improve the loading and unloading efficiency, but also reduce the cost and shorten the service network time; Wang Shuyun and Sun Hong through the mechanical and cold storage model of multi-temperature co-modeling analysis, proved that the cold storage of multi-temperature co-distribution is more effective.

\section{MODEL ESTABLISHMENT}

\section{A. Problem Description}

Assumed that there is one distribution center and many service outlets in a city, the cooling-storage multi-temperature joint distribution has been adopted to transport $s$ types of coldchain products with different temperatures. $t_{i j k}$ is the driving time of the vehicle $k$ on the route of $(i, j), t_{i j k} \sim N\left(u_{i j}, \sigma_{i j}^{2}\right), u_{i j}$ is the average value of the driving time following the distribution function on the route $(i, j) . \sigma_{i j}$ is the standard deviation of the driving time following the distribution function the route $(i, j) . q$ is the service quality on the route $(i$, j) during the driving time. The distribution center will plan the distribution route based on the driving time following the distribution known and the service quality on a certain route during the driving time. 


\section{B. Model Assumptions}

The needs of service outlet can be satisfied by the distribution center. The needs and distribution time window of each cold-chain product in the service outlet have been made clear. The starting and ending point of the vehicle are in the distribution center. There is a loading limit for each vehicle. The volume of cold-chain transport should not exceed the rated loading capacity. The vehicles of the same type will be used for distribution. The cold-chain product with different needs should be transported by one vehicle, which will be completed one time.

\section{Related Parameters}

$\mathrm{J}$ is the collection of service sites; $\mathrm{K}$ is the collection of transport vehicles; $S$ is the collection of cold chain types; $Q_{j s}$ is the demand for the $s^{\text {th }}$ cold-chain product in the service outlet $\mathrm{j} ; \mathrm{P}_{\mathrm{s}}$ is the price of each cold chain products; $M$ and $\mathrm{M}_{\mathrm{s}}$ are the rated loading capacity and the rated weight for different products. $Y_{j k}$ is the variable, which is 0 or 1 . If the vehicle $\mathrm{k}$ is used for the distribution for the service outlet $\mathrm{j}$, it will be 1 . Otherwise, it will be $0 . \mathrm{X}_{\mathrm{ijk}}$ is the variable, which is 0 or 1 . If the vehicle $\mathrm{k}$ moves between the service outlets $\mathrm{i}$ and the service outlet $j$, it will be 1 . Otherwise, it will be $0 . S_{i j}$ is the driving time saved on the route $(i, j)$ for the vehicle $k$. $S_{i j}=2\left(t_{0 j}+t_{0 i}\right)-\left(t_{0 i}+t_{0 j}-t_{i j}\right)$

\section{FORMULATE THE OBJECTIVE FUNCTION}

\section{A. Driving Cost}

Driving costs include the fuel consumption during vehicles traveling, bridge and road tolls and maintenance costs, proportional to the travel time. $\mathrm{c}_{\mathrm{s}}$ is the driving cost for each cold-chain product for each unit of time and quality. The driving cost is as follows.

$$
\mathrm{C}_{1}=\sum_{\mathrm{i} \in \mathrm{J}} \sum_{\mathrm{j} \in \mathrm{J}} \sum_{\mathrm{k} \in \mathrm{K}} \sum_{\mathrm{s} \in \mathrm{S}} \mathrm{X}_{\mathrm{ijk}} \mathrm{c}_{\mathrm{s}} \mathrm{Q}_{\mathrm{js}} \mathrm{t}_{\mathrm{ijk}}
$$

\section{B. The Cost of Cargo Damage}

The cost of cargo damage will occur during the long-time transport and unloading of the cold-chain products. Because of the different features of cold-chain products and different temperatures during the distribution, the proportion of cargo damage during the transport and unloading will also change. $\theta_{1}^{\text {s }}$ and $\theta_{2}^{\text {s }}$ are the proportions of cargo damage during the transport and unloading for each cold-chain product. The cost of cargo damage is as follows.

$$
\mathrm{C}_{2}=\mathrm{P}_{\mathrm{s}} \sum_{\mathrm{i} \in \mathrm{J}} \sum_{\mathrm{j} \in \mathrm{J}} \sum_{\mathrm{k} \in \mathrm{K}} \sum_{\mathrm{s} \in \mathrm{S}} \mathrm{Y}_{\mathrm{jk}}\left(\theta_{1}^{\mathrm{s}} \mathrm{t}_{\mathrm{ijk}}+\theta_{2}^{\mathrm{s}} \mathrm{Q}_{\mathrm{js}}\right)
$$

\section{The Cost of Thermal Insulation Box}

The cost of the thermal insulation box is the purchase fee, the warranty fee and the depletion fee of the cooling equipment. $\mathrm{N}_{\mathrm{k}}^{\mathrm{S}}$ is the number of thermal insulation box for the $\mathrm{s}^{\text {th }}$ cold-chain product in the vehicle. $c_{b}$ is price of thermal insulation box. The cost of thermal insulation box is as follows.

$$
\mathrm{C}_{3}=\sum_{\mathrm{k} \in \mathrm{K}} \sum_{\mathrm{s} \in \mathrm{S}} \mathrm{c}_{\mathrm{b}} \mathrm{N}_{\mathrm{k}}^{\mathrm{s}}
$$

\section{The Penalty Cost of Time Window}

The distribution time window of the service outlet $j$ is $\left[t_{j a}, t_{j b}\right]$. The acceptable time window is $\left[t_{j A}, t_{j B}\right]$.If the vehicle arrives before $t_{j A}$ after $t_{j B}$, the vehicle will receive the penalty. If it arrives within the period of $\left[t_{j a}, t_{j b}\right]$, it will not receive any penalty. If it arrives within the period of $\left[t_{j A}\right.$, $\left.t_{j a}\right]$ or $\left[t_{j b}, t_{j B}\right]$, it will receive the penalty in varying degrees. The penalty coefficient for the unit of time is $\lambda_{1}$ and $\lambda_{2}$. The time window penalty cost function $C_{j}$ has been formed for one service outlet.

$$
C_{j}=\left\{\begin{array}{lr}
t_{j x}<t_{j A}, \quad t_{j x}>t_{j B} \\
\sum_{s \in S} \lambda_{1} P_{s} Q_{j s}\left(t_{j a}-t_{j x}\right), \quad t_{j A}<t_{j x}<t_{j a} \\
\sum_{s \in S} \lambda_{2} P_{s} Q_{j s}\left(t_{j x}-t_{j b}\right), & t_{j b}<t_{j x}<t_{j B} \\
0, & t_{j a}<t_{j x}<t_{j b}
\end{array}\right.
$$

The penalty cost of time window is as follows.

$$
\mathrm{C}_{4}=\sum_{\mathrm{j} \in \mathrm{J}} \mathrm{C}_{\mathrm{j}}
$$

\section{E. The Penalty Cost of Cargo Damage Rate}

In real life, a large amount of loss may be caused by many factors, such as the malfunction of heat insulation box, during the transport. Even if the vehicle arrives within the given time, the goods will be also rejected by the service outlet. In this paper, the cargo damage occurring during the long-distance transport and unloading process will be considered. Hence, the rate of cargo damage for each cold-chain product between different service outlets is as follows.

$$
H_{i j}^{s}=Y_{j k}\left(\theta_{1}^{s} t_{i j k}+\theta_{2}^{s} Q_{j s}\right) \div Q_{j s}, i, j \in J, i \neq j, \forall k, \forall s
$$

Considering that the service outlet has set a standard on the cargo-damage rate, it will not be punished if the cargo-damage rate for each cold-chain product falls within the acceptable level of the service outlet $\mathrm{j}$. If not, it will be punished. If it exceeds the upper limit of the acceptable level, the penalty will be intensified accordingly. $\lambda_{3}^{s}$ is the penalty coefficient for the cargo-damage rate per unit for each cold-chain product. $\mathrm{H}_{\mathrm{j} 1}^{\mathrm{s}}$ and $\mathrm{H}_{\mathrm{j} 2}^{\mathrm{s}}$ are the lower limit and upper limit of the acceptable cargo-damage rate for each cold-chain product in the service outlet $\mathrm{j}$. The penalty cost of cargo-damage rate for each cold-chain product in the service outlet $\mathrm{j}$ is as follows.

$$
C_{j}^{s}=\left\{\begin{array}{l}
0, \quad H_{i j}^{s}<H_{j 1}^{s} \\
\lambda_{3}^{s} P_{s} Q_{j s}\left(H_{i j}^{s}-H_{j 1}^{s}\right), H_{j 1}^{s}<H_{i j}^{s}<H_{j 2}^{s} \\
\infty, \quad H_{i j}^{s}>H_{j 2}^{s}
\end{array}\right.
$$

The penalty cost of cargo damage rate is as follow.

$$
\mathrm{C}_{5}=\sum_{\mathrm{j} \in \mathrm{J}} \sum_{\mathrm{s} \in \mathrm{S}} \mathrm{C}_{\mathrm{j}}^{\mathrm{s}}
$$

\section{F. Distribution Optimization Model}

In summary, the objective function is as follow.

$$
\begin{aligned}
& \operatorname{MinC}=\mathrm{C}_{1}+\mathrm{C}_{2}+\mathrm{C}_{3}+\mathrm{C}_{4}+\mathrm{C}_{5}=\sum_{\mathrm{i} \in \mathrm{J}} \sum_{\mathrm{j} \in \mathrm{J}} \sum_{\mathrm{k} \in \mathrm{K}} \sum_{\mathrm{s} \in \mathrm{S}} \mathrm{X}_{\mathrm{ijk}} \\
& \mathrm{c}_{\mathrm{s}} \mathrm{Q}_{\mathrm{js}} \mathrm{t}_{\mathrm{ijk}}+\mathrm{P}_{\mathrm{s}} \sum_{\mathrm{i} \in \mathrm{J}} \sum_{\mathrm{j} \in \mathrm{J}} \sum_{\mathrm{k} \in \mathrm{K}} \sum_{\mathrm{s} \in \mathrm{S}} \mathrm{Y}_{\mathrm{jk}}\left(\theta_{1}^{s} \mathrm{t}_{\mathrm{ijk}}+\theta_{2}^{\mathrm{s}} \mathrm{Q}_{\mathrm{js}}\right)+ \\
& \sum_{\mathrm{k} \in \mathrm{K}} \sum_{\mathrm{s} \in \mathrm{S}} \mathrm{c}_{\mathrm{b}} \mathrm{N}_{\mathrm{k}}^{\mathrm{s}}+\sum_{\mathrm{j} \in \mathrm{J}} \mathrm{C}_{\mathrm{j}}+\sum_{\mathrm{j} \in \mathrm{J}} \sum_{\mathrm{s} \in \mathrm{S}} \mathrm{C}_{\mathrm{j}}^{\mathrm{s}} \\
& \text { st: } \sum_{\mathrm{j} \in \mathrm{J}} \sum_{\mathrm{s} \in \mathrm{S}} \mathrm{Y}_{\mathrm{jk}} \mathrm{Q}_{\mathrm{js}} \leq \mathrm{M} \\
& \sum_{\mathrm{j} \in \mathrm{J}} \mathrm{Y}_{\mathrm{jk}} \mathrm{Q}_{\mathrm{js}} \leq \mathrm{M}_{\mathrm{s}}
\end{aligned}
$$




$$
\begin{array}{r}
\mathrm{t}_{\mathrm{jA}}<\mathrm{t}_{\mathrm{jx}}<\mathrm{t}_{\mathrm{jB}} \\
\sum_{\mathrm{j} \in \mathrm{J}} \sum_{\mathrm{k} \in \mathrm{K}} \mathrm{X}_{\mathrm{ijk}}=1, \forall \mathrm{j} \in \mathrm{J} \\
\sum_{\mathrm{i} \in \mathrm{J}} \sum_{\mathrm{j} \in \mathrm{J}} \sum_{\mathrm{k} \in \mathrm{K}} \mathrm{X}_{\mathrm{ijk}}=\sum_{\mathrm{i} \in \mathrm{J}} \sum_{\mathrm{j} \in \mathrm{J}} \sum_{\mathrm{k} \in \mathrm{K}} \mathrm{X}_{\mathrm{jik}} \\
\mathrm{P}\left\{\sum_{\mathrm{i} \in \mathrm{J}} \sum_{\mathrm{j} \in \mathrm{J}} \mathrm{X}_{\mathrm{ijk}} \mathrm{t}_{\mathrm{ijk}} \leq \mathrm{B}\right\}>q
\end{array}
$$

(9) is the optimization target; (10) is the vehicle load limit; (11) is the weight limit for each cold chain product; (12) is a time window constraint; (13) for each service site, only one car for its distribution; (14) vehicle is at the distribution site at the beginning and the end; (15) In order to ensure the running time of the established line, B is set to be the maximum travel time of the vehicle.

\section{MOdel SOlving}

In the distribution, the cost of travel and the cost of cargo damage are proportional to the travel time, so the calculation of cost savings can be used for comparison just by the calculation of the saving of travel costs, carbon and tax costs. The improved objective function is as follow.

$$
\operatorname{Max} \mathrm{Y}=\sum_{\mathrm{i} \in \mathrm{J}} \sum_{\mathrm{j} \in \mathrm{J}} \sum_{\mathrm{s} \in \mathrm{s}}\left[\left(\mathrm{c}_{\mathrm{s}} \mathrm{Q}_{\mathrm{js}}+\mathrm{P}_{\mathrm{s}} \theta_{1}^{\mathrm{s}}\right) \times \mathrm{S}_{\mathrm{ij}}\right]-\mathrm{C}_{4}-\mathrm{C}_{5}
$$

The model built above is based on the non-linear planning. Hence, it cannot be solved through the linear planning software. In most cases, the saving algorithm will be used to simplify the solving of the problem [10].The concrete steps are as follows (1): Rank the time window order of the various networks; (2): Calculate the saving value of the distance $\mathrm{S}_{\mathrm{ij}}$; (3): The model regard the network that requires the earliest outlets as the primary service providers, Starting from the distribution center, and then search network according to the principle of the lowest cost ;(4): Repeat step (3) until the line reaches the limit of vehicle or some kind of cold chain load capacity; (5): Repeat step (3) and step (4) until all outlets are discharged into the line.

\section{Calculation CASE Analysis}

In order to verify the effectiveness of the model above, this paper has chosen a distribution center delivering two coldchain products of different temperatures to 10 service outlets as an example. Provided that the driving time on each route follows the independent normal distribution, the service quality of driving time on the given route is not lower than 95 percent. For all distribution centers, the vehicles with the loading capacity of 3 tons will be used. The distribution volume of each cold-chain product is 1.5 tons. For the coldchain product 1 and 2, the transport cost for each unit of quality and time is 5 Yuan/ton per minute. Hence, the unit price is $6000 \mathrm{Yuan} / \mathrm{ton}$ and $5000 \mathrm{Yuan} / \mathrm{ton}$. The proportion of cargo-damage loss during the transport is 0.01 percent and 0.03 percent respectively. The proportion of cargo-damage loss during the unloading is 0.1 percent and 0.2 percent respectively. The upper limit and lower limit of the acceptable cargo-damage loss rate for each cold-chain product in the service outlet is 10 percent and 5 percent respectively. It will take 20 minutes to finish the unloading for each customer. The fixed cost of each vehicle is 800 Yuan. The carbon emission of cold-chain product for each unit of quality and time is 20 gram/ton per minute. $\lambda_{3}^{s}$ is 1 . The price of carbon emission is

\begin{tabular}{|c|c|c|c|c|c|}
\hline $\begin{array}{l}\text { Service } \\
\text { outlets }\end{array}$ & 1 & 2 & 3 & 4 & 5 \\
\hline $\begin{array}{l}\text { Cold-chain } \\
\text { product } 1\end{array}$ & 0.4 & 0.3 & 0.6 & 0.5 & 0.4 \\
\hline $\begin{array}{l}\text { Cold-chain } \\
\text { product } 1\end{array}$ & 0.6 & 0.4 & 0.6 & 0.3 & 0.3 \\
\hline $\begin{array}{l}\text { Window of } \\
\text { the service } \\
\text { outlet }\end{array}$ & $6: 35-7: 05$ & $6: 30-7: 00$ & $5: 35-6: 05$ & $7: 05-7: 35$ & $6: 15-6: 45$ \\
\hline $\begin{array}{l}\text { Acceptable } \\
\text { time } \\
\text { window }\end{array}$ & $6: 05-7: 35$ & $6: 00-7: 30$ & $5: 05-6: 35$ & $6: 35-8: 05$ & $5: 45-7: 15$ \\
\hline $\begin{array}{l}\text { Service } \\
\text { outlets }\end{array}$ & 6 & 7 & 8 & 9 & 10 \\
\hline $\begin{array}{l}\text { Window of } \\
\text { the service } \\
\text { outlet }\end{array}$ & 0.4 & 0.3 & 0.5 & 0.5 & 0.4 \\
\hline $\begin{array}{l}\text { Acceptable } \\
\text { time } \\
\text { window }\end{array}$ & 0.4 & 0.5 & 0.3 & 0.5 & 0.6 \\
\hline $\begin{array}{l}\text { Cold-chain } \\
\text { product } 1\end{array}$ & $5: 50-6: 20$ & $5: 55-6: 25$ & $7: 00-7: 30$ & $7: 00-7: 30$ & $7: 40-8: 10$ \\
\hline $\begin{array}{l}\text { Cold-chain } \\
\text { product } 1\end{array}$ & $5: 20-6: 50$ & $5: 25-6: 55$ & $6: 30-8: 00$ & $6: 30-8: 00$ & $7: 10-8: 40$ \\
\hline
\end{tabular}
0.02 Yuan/ton per minute. The penalty coefficient $\lambda_{1}$ and $\lambda_{2}$ for each unit of time are 0.2 percent and 0.3 percent respectively.

TABLE I. REQUIREMENTS AND TIME WINDOW OF THE 10BRANCH DISTRIBUTION 
TABLE II. DISTRIBUTION CENTER I DISTANCE BETWEEN THE LINE, TRAVEL TIME OBEY THE DISTRIBUTION FUNCTION OF THE MEAN AND STANDARDDEVIATION $\left(\mathrm{D}_{\mathrm{IJ}} \cdot \mathrm{U}_{\mathrm{IJ}} \cdot \mathrm{c}_{\mathrm{IJ}}\right)$

\begin{tabular}{|c|c|c|c|c|c|c|c|c|c|c|c|}
\hline & $\mathbf{I}$ & 1 & 2 & 3 & 4 & 5 & 6 & 7 & 8 & 9 & 10 \\
\hline I & 0 & & & & & & & & & & \\
\hline 1 & $\begin{array}{l}10 \\
30,9\end{array}$ & 0 & & & & & & & & & \\
\hline 2 & $\begin{array}{l}10 \\
20,9\end{array}$ & $\begin{array}{l}6 \\
12,4\end{array}$ & 0 & & & & & & & & \\
\hline 3 & $\begin{array}{l}8 \\
19,8\end{array}$ & $\begin{array}{l}4 \\
12,9\end{array}$ & $\begin{array}{l}5 \\
10,4\end{array}$ & 0 & & & & & & & \\
\hline 4 & $\begin{array}{l}10 \\
30,4\end{array}$ & $\begin{array}{l}5 \\
10,9\end{array}$ & $\begin{array}{l}4 \\
10,4\end{array}$ & $\begin{array}{l}4 \\
8,4\end{array}$ & 0 & & & & & & \\
\hline 5 & $\begin{array}{l}5 \\
12,4\end{array}$ & $\begin{array}{l}7 \\
14,4\end{array}$ & $\begin{array}{l}8 \\
24,9\end{array}$ & $\begin{array}{l}5 \\
10,9\end{array}$ & $\begin{array}{l}7 \\
14,9\end{array}$ & 0 & & & & & \\
\hline 6 & $\begin{array}{l}6 \\
12,4\end{array}$ & $\begin{array}{l}6 \\
12,4\end{array}$ & $\begin{array}{l}6 \\
12,9\end{array}$ & $\begin{array}{l}6 \\
18,9\end{array}$ & $\begin{array}{l}6 \\
18,4\end{array}$ & $\begin{array}{l}4 \\
8,8\end{array}$ & 0 & & & & \\
\hline 7 & $\begin{array}{l}8 \\
16,8\end{array}$ & $\begin{array}{l}6 \\
14,6\end{array}$ & $\begin{array}{l}5 \\
10,8\end{array}$ & $\begin{array}{l}6 \\
12,4\end{array}$ & $\begin{array}{l}4 \\
8,9\end{array}$ & $\begin{array}{l}8 \\
24,9\end{array}$ & $\begin{array}{l}7 \\
14,8\end{array}$ & 0 & & & \\
\hline 8 & $\begin{array}{l}7 \\
14,5\end{array}$ & $\begin{array}{l}5 \\
15,5\end{array}$ & $\begin{array}{l}5 \\
15,9\end{array}$ & $\begin{array}{l}5 \\
10,4\end{array}$ & $\begin{array}{l}5 \\
15,9\end{array}$ & $\begin{array}{l}6 \\
14,9\end{array}$ & $\begin{array}{l}7 \\
21,4\end{array}$ & $\begin{array}{l}4 \\
8,16\end{array}$ & 0 & & \\
\hline 9 & $\begin{array}{l}4 \\
10,4\end{array}$ & $\begin{array}{l}8 \\
24,4\end{array}$ & $\begin{array}{l}8 \\
24,4\end{array}$ & $\begin{array}{l}8 \\
24,5\end{array}$ & $\begin{array}{l}8 \\
24,4\end{array}$ & $\begin{array}{l}4 \\
10,4\end{array}$ & $\begin{array}{l}4 \\
10,4\end{array}$ & $\begin{array}{l}6 \\
18,9\end{array}$ & $\begin{array}{l}5 \\
10,9\end{array}$ & 0 & \\
\hline 10 & $\begin{array}{l}5 \\
12,4\end{array}$ & $\begin{array}{l}8 \\
16,8\end{array}$ & $\begin{array}{l}7 \\
14,9\end{array}$ & $\begin{array}{l}8 \\
24,7\end{array}$ & $\begin{array}{l}7 \\
14,8\end{array}$ & $\begin{array}{l}4 \\
10,8\end{array}$ & $\begin{array}{l}4 \\
10,9\end{array}$ & $\begin{array}{l}7 \\
14,4\end{array}$ & $\begin{array}{l}7 \\
14,9\end{array}$ & $\begin{array}{l}4 \\
10,4\end{array}$ & 0 \\
\hline
\end{tabular}

According to probability theory, $\mathrm{X} \sim\left(\mathrm{u}, \sigma^{2}\right)$, when the satisfaction rate of the established travel time is $95 \%$, the data is substituted into the improved objective function. The LINGO calculation is used to determine the line arrangement and cost saving under the condition of determined driving time and random travel time. See tab. 3.

TABLE III. TWO KINDS OF DIVIDING NETWORK LINE ARRANGMENT AND COST COMPARISION

\begin{tabular}{cll}
\hline & Random driving time & Determine the travel time \\
\hline Distribution line & I-5-1-9-I,I-4-10-I & I-5-6-9-I,I-10-I \\
& I-3-2-6-I,I-7-8-I & I-3-1-8-I,I-7-2-4-I \\
Save costs & 944.42 Yuan & 749.94 Yuan \\
\hline
\end{tabular}

As can be seen from tab. 3 , the solution to the problem can be better found according to the actual requirements of random time conditions and gets a lower cost of the scheduling program to meet the dynamic conditions of the distribution requirements, so the model and method are valid and feasible.

\section{CONCLUSION}

This paper is mainly concerned with the optimization and selection of the multi-temperature cold-chain under the dynamic environment. The saving algorithm has been used to optimize the distribution route. The calculation case has been utilized to compare the difference in the distribution route between stochastic mode and deterministic model. The research significance of this model is that it can allow for the change in the driving time on the road. On condition that the driving time change still follows the original distribution, the existing route planning can be still adopted. Although the route planning may not be optimal for a certain distribution under the uncertain condition, it is still optimal in the long term. Therefore, this model is worthy of being promoted and recommended.

\section{REFERENCES}

[1] Wang Shuyun, Sun Hong, Mou Jinjin, JIN Hui. Optimization and Efficiency of Multi-temperature Joint Distribution of Cold Chain Products: Comparative Study Based on Cold Accumulation Model and Mechanical Refrigeration Mode [J]. Journal of Highway and Transportation Research and Development, 2016, 33(3): 146-153.( In Chinese)

[2] Lv Junjie, Sun Shuangshuang. Study on vehicle routing of fresh agricultural products in cold-chain [J]. Guangdong Agricultural Sciences, 2013, 40(9): 178-181.( In Chinese)

[3] Zhang Yaming, LI Na. Research on Elite Selection Based Parthenongenetic Under Optimized Cold-chain Logistics VRP Model [J]. Mathematics in Practice and Theory, 2016, 46(4): 87-96.( In Chinese)

[4] CHO Y J, LI C C. Application of multi-temperature refrigerated container to improve the distribution of cold logistics [J].Journal of the Eastern Asia Society for Transportation Studies .2005, 6: 2794-2808.

[5] KUO J C, CHEN M C. Developing an advanced multi-temperature joint distribution system for the food cold chain [J].Food Control. 2010, 21(4):559-566.

[6] HSU C I, LIU K P.A Model for facilities planning for multi-temperature joint distribution system [J].Food Control, 2013, 22(12):1873-1882.

[7] Wang Shuyun, Zhao Min. Impetus of Multi-temperature Joint Distribution Based on Storage Cold-chain Logistics [J]. Journal of Highway Transportation Research and Development, 2012, 29(2):144148.( In Chinese)

[8] HSU C, CHEN W, WU W. Optimal delivery cycles for joint distribution of multi-temperature food [J]. Food Control, 2013, 34(1): 106-114.

[9] DAVID L, GIRMA G. Mapping out the potential for coordinated goods distribution in city centers: The case of Uppsala [J]. International Journal of Transport Management, 2004, 34(2):161-172.

[10] Clarke G, Wright J W. Scheduling of vehicles from a central depot to a number of delivery point [J]. Operation Research, 1964, 12:568-581. 